\title{
Application of quantitative impulse thermography for structural evaluation in civil engineering - Comparison of experimental results and numerical simulations
}

\author{
by A. Brink, Ch. Maierhofer, M. Röllig and H. Wiggenhauser
}

Federal Institute for Materials Research and Testing (BAM), Division IV.4: Non-destructive Damage Assessment and Environmental Measurement Methods,

Unter den Eichen 87, D-12205 Berlin, Germany, e-mail: Arne.Brink@bam.de

\begin{abstract}
The cooling-down process of building structures after heating-up with an external radiation source was analysed to detect voids inside and below the surface. Here, the results of a concrete test specimen containing voids with different sizes at various depths will be presented. These experimental investigations were compared to the results of simulations performed with a Finite Difference program.
\end{abstract}

\section{Introduction}

Impulse thermography is an active approach for a quantitative thermal scanning of the surface of various structures and elements [1]. It is well known for material testing in other industry branches for the detection of voids and delaminations [2]. In civil engineering, the application of infrared thermography was mostly limited to passive investigations of the quality of thermal insulation of building envelopes. Only a few examples show that the active method is very useful for locating defects in the near surface region. One example is the determination of the built-in position of anchoring elements at curtain facades [3]. Further developments and applications in civil engineering are using the sun as a natural heat source. Examples are inspections of bridge decks [4] and of paving in general [5]. For locating delaminations at bridge decks, an ASTM standard, published 1988 with the title Standard Test Method for Detecting Delaminations in Bridge Decks Using Infrared Thermography [6], exists.

Within the scope of a national project funded by the DFG (Deutsche Forschungsgemeinschaft, organisation for academic research in Germany) the application of impulse thermography as a non-destructive testing method in civil engineering [7][8][9] is investigated. In a co-operation work between the Technical University of Berlin and the Federal Institute for Materials Research and Testing (BAM) the technique is intended for the detection of near-surface inhomogeneities, normally defects, in typical structural elements and for the determination of their geometrical parameters. In this research project practical problems like locating voids and honeycombing in concrete, delaminations of plaster at concrete and masonry, delaminations and voids behind tiles on concrete embedded in mortar, interconnection of carbon fibre reinforced laminates glued on concrete and delaminations of bituminous sealing on steel are analysed.

Measurements were performed by heating the surface of the specimen under investigation. The heating pulse causes a non stationary heat flow. The propagation of the heat is a physical process and depends on the material properties like thermal conductivity, heat capacity and density. The spatial propagation is evenly only for homogeneous material. If there are inhomogeneities in the structural element with different thermal properties, the heat flow will slow down or accelerate in these local areas. While observing the temporal changes of the surface temperature distribution with the infrared camera, near surface inhomogeneities will be detected if they give rise to measurable temperature differences on the surface. The differences between temperature transient curves at surface positions above non-defect regions and above 
inhomogeneities include information about the defect parameters like depth, lateral size and the type of material.

In this paper, the results of the investigations of a concrete test specimen containing voids with different sizes at various depths will be presented. The experimental data are compared to results of simulations using a Finite Difference program based of the Fourier equation.

\section{Experimentals}

The experimental set-up for the performance of impulse thermography measurements consists of a thermal heating unit, an infrared camera and a computer system which enables digital data recording in real time.

The thermal heating unit contains three infrared radiators each having a power of 2400 W. The heating-up procedure is usually done dynamically by moving the radiators computer controlled to obtain the best possible homogeneous heating. Therefore, radiators are mounted in a line array and are moved vertical to this array and parallel to the surface at a distance of about $15 \mathrm{~cm}$.

The cooling-down process of the surface is observed with an infrared camera (Inframetrics SC1000). The camera detects the emitted radiation from the surface of the specimen in a wavelength region from 3 to $5 \mu \mathrm{m}$. The camera has a focal plane array of 256x256 semiconductor detectors (PtSi). Each detector measures the intensity of the radiation. These values can be presented on a monitor as grey or colour scaled thermal images and can be converted into temperature values using look-up tables.

During the measurements the thermal images are transferred to a computer at a maximum frequency of $50 \mathrm{~Hz}$ and a storage depth of 12 bits of each pixel. After receiving the thermal images the computer is also used to analyse the data with dedicated software programs.

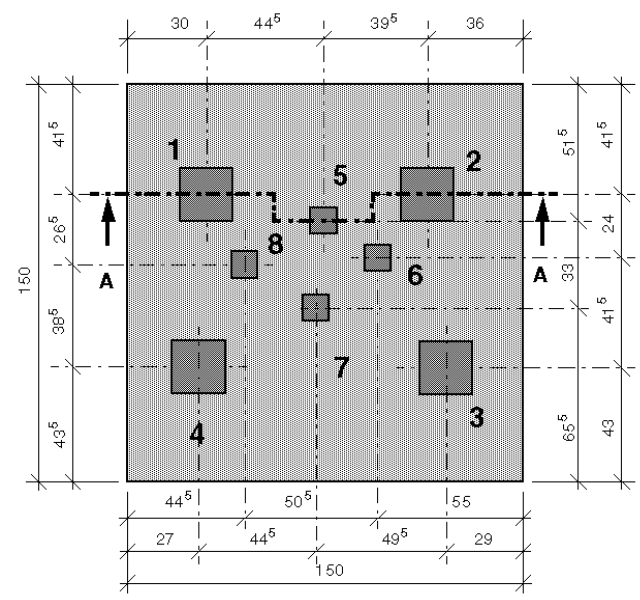

Schnitt A - A

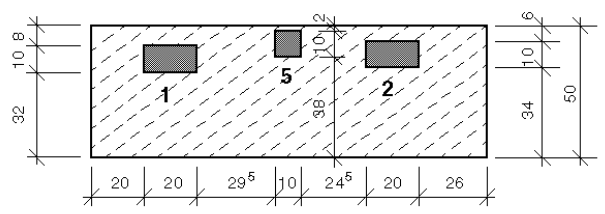

Fig. 1. Sketch of the concrete test specimen (units in $\mathrm{cm}$ ). 
Typical testing problems for civil engineering are voids and honeycombing in concrete elements. Therefore a test specimen was built having a size of $150 \times 150 \times 50 \mathrm{~cm}^{3}$ containing voids with different sizes $\left(10 \times 10 \times 10 \mathrm{~cm}^{3}\right.$ and $\left.20 \times 20 \times 10 \mathrm{~cm}^{3}\right)$ and concrete covers as displayed in figure 1 . Six measurements were performed by heating the surface of the specimen with varied heating times from 5 to $60 \mathrm{~min}$. After switching off the heat source the cooling-down process was monitored with the infrared camera and thermal images were recorded with a rate of $2 \mathrm{~Hz}$ for a duration of $120 \mathrm{~min}$. During data conversion, the average of 10 images was determined for noise reduction. The result for data analysis is a film of 1440 images with a time step of $5 \mathrm{~s}$ between single images.

Figure 2 shows a thermogram selected from a measurement series with $15 \mathrm{~min}$ heating time. The thermogram was taken $8.1 \mathrm{~min}$ after switching off the radiators. The shallow voids have a good contrast after short cooling-down time while the deep voids cannot be detected so far but appear clearly after waiting for longer times (50 min).

The main approach in analysing the thermal data was to interpret the function of surface temperature versus cooling time (figure 3 ) for selected areas with and without inhomogeneities (figure 2). These selected transient curves were compared and difference curves (difference between transient above a void and transient above a sound area) were calculated as shown in figure 3 . The difference curves usually have a maximum of the temperature difference $\Delta T_{\max }$ at a distinct time $t_{\Delta T \max }$ which depends mainly on the depth of the void and the heating time. The values of $\Delta T_{\max }$ and $t_{\Delta T \max }$ for each void for the series after 15 min of heating are presented in table 1.

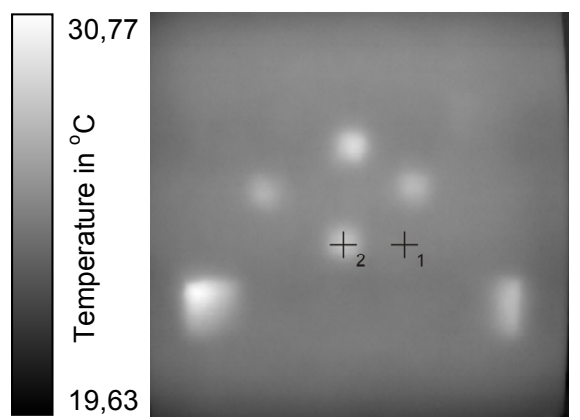

Fig. 2. Thermogram recorded $8.1 \mathrm{~min}$ after switching off the heat source. The heating time was $15 \mathrm{~min}$.

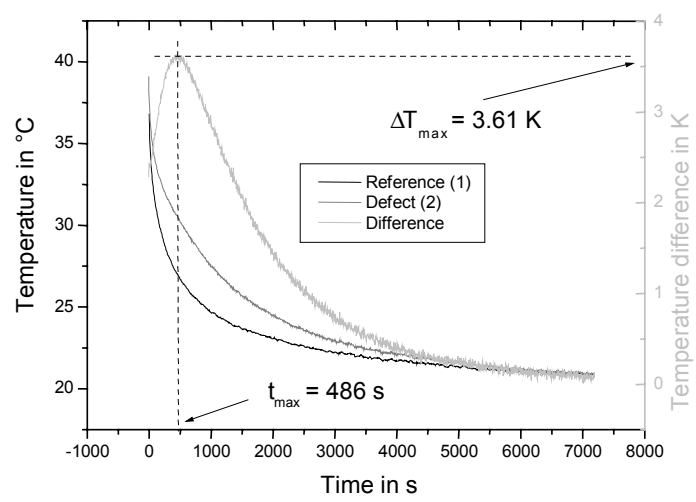

Fig. 3. Temperature versus time curves for selected areas (figure 2) and the respected difference curve with a maximum temperature difference at a distinct time. 


\section{Simulations}

Numerical calculations based on the Finite Differences method were carried out for further data interpretation and for solving the Inverse Problem. The program simulates a heating pulse on the surface of the specimen for a defined heating time and calculates the heat flow inside the specimen. Surface losses are taken into account during the whole calculation. The result of the simulation is an array, which contains the temperature distribution for all surface nodes at every time step of heating and cooling-down.

By varying environmental conditions and measurement parameters the influence of the single parameters on the results of impulse thermography measurements was investigated. It came out that it will have nearly no influence on $\Delta T_{\max }$ and $t_{\Delta T_{\max }}$ if the specimen is heated with a static or periodic pulse with an oscillation time of $15 \mathrm{~s}$. Varying the ambient temperature does not cause any changes on $\Delta T_{\max }$ and $t_{\Delta T \max }$, too. The amount of heat has a linear influence on $\Delta T_{\max }$ but does not affect $t_{\Delta T \max }$. Surface losses and material parameters should be well known, as their effect cannot be calculated easily. $\Delta T_{\max }$ and $t_{\Delta T_{\max }}$ increase with the defect size approximating to limits at which the defect can be considered as an own layer. The main impact on $\Delta T_{\max }$ and $t_{\Delta T \max }$ refers to heating time and defect depth. As the heating time is well known, its effect is less important for the comparison of simulated and measured values.

For the comparison of simulated and measured results numerical simulations were carried out for the same heating times used for the real measurements varying the defect depth from 1 to $10 \mathrm{~cm}$. Figure 4 left shows simulated temperature difference curves with different defect depths for 15 min heating time.

Determining $\Delta T_{\max }$ and $t_{\Delta T \max }$ from these simulated curves for all heating times makes it possible to describe $\Delta T_{\max }$ and $t_{\Delta T \max }$ depending on the defect depth. Figure 4 right represents a diagram where the time of the maximum temperature difference is plotted as a function of defect depth.

With the help of this diagram the real concrete cover of the voids of the specimen can be ascertained using the experimentally determined values of $t_{\Delta T \max }$ from table 1 . By analogy, the same procedure can be performed for the other heating time series. The results of this analysis are shown in table 2. For the shallow void no. 7 the heating times of $45 \mathrm{~min}$ and $60 \mathrm{~min}$ were too long to receive a maximum temperature difference, due to the temperature above the void being out of range.
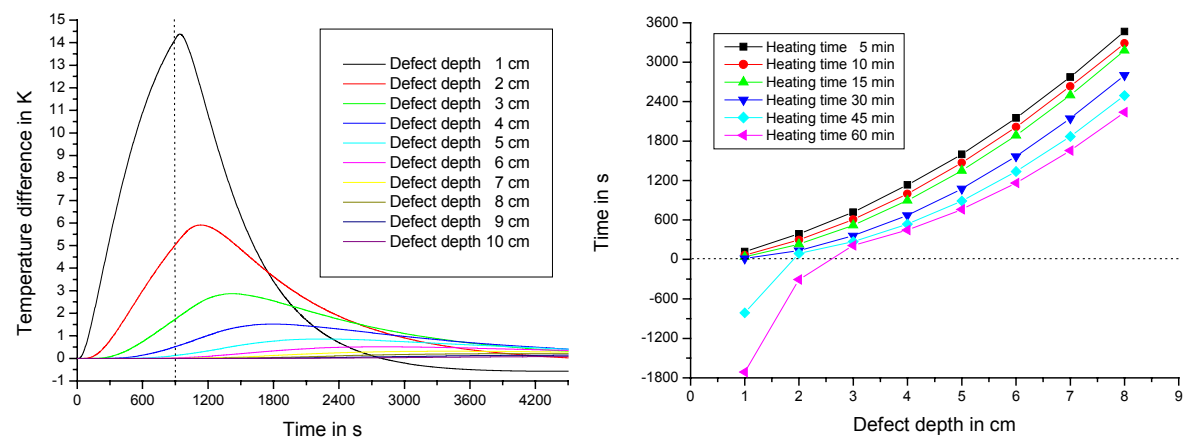

Fig. 4. Left: Simulated temperature difference curves with different defect depths for $15 \mathrm{~min}$ heating time. Right: Time of maximum temperature difference forvarious defect depths and heating times. 
Table 1: Maximum temperature difference and distinct time for the voids after 15 min of heating.

\begin{tabular}{|c|c|c|c|c|}
\hline void no. & $\begin{array}{c}\text { seize } \\
\text { in } \mathrm{cm}^{3}\end{array}$ & $\begin{array}{c}\text { nominal depth } \\
\text { in cm }\end{array}$ & $\begin{array}{c}\Delta \mathrm{T}_{\max } \\
\text { in } \mathrm{K}\end{array}$ & $\begin{array}{c}\mathrm{t}_{\Delta \mathrm{Tmax}} \\
\text { in s }\end{array}$ \\
\hline 1 & $20 \times 20 \times 10$ & 8 & 0,73 & 3125 \\
\hline 2 & $20 \times 20 \times 10$ & 6 & 1,45 & 2445 \\
\hline 3 & $20 \times 20 \times 10$ & 4 & 2,33 & 1485 \\
\hline 4 & $20 \times 20 \times 10$ & 2 & 4,71 & 940 \\
\hline 5 & $10 \times 10 \times 10$ & 2 & 3,45 & 485 \\
\hline 6 & $10 \times 10 \times 10$ & 4 & 2,96 & 585 \\
\hline 7 & $10 \times 10 \times 10$ & 6 & 5,48 & 280 \\
\hline 8 & $10 \times 10 \times 10$ & 8 & 2,62 & 605 \\
\hline
\end{tabular}

Table 2: Determination of the defect depth by Inverse Solution.

\begin{tabular}{|c|c|c|c|c|c|c|}
\cline { 2 - 7 } \multicolumn{1}{c|}{} & \multicolumn{6}{c|}{ heating time } \\
\cline { 2 - 7 } \multicolumn{1}{c|}{} & \multicolumn{2}{c|}{$300 \mathrm{~s}$} & \multicolumn{2}{c|}{$600 \mathrm{~s}$} & \multicolumn{2}{c|}{$900 \mathrm{~s}$} \\
\hline $\begin{array}{c}\text { void } \\
\text { no. }\end{array}$ & $\begin{array}{c}\mathrm{t}_{\Delta T \max } \\
\text { in s }\end{array}$ & $\begin{array}{c}\text { depth } \\
\text { in cm }\end{array}$ & $\begin{array}{c}\mathrm{t}_{\Delta \mathrm{Tmax}} \\
\text { in s }\end{array}$ & $\begin{array}{c}\text { depth } \\
\text { in cm }\end{array}$ & $\begin{array}{c}\mathrm{t}_{\Delta \mathrm{Tmax}} \\
\text { in s }\end{array}$ & $\begin{array}{c}\text { depth } \\
\text { in } \mathrm{cm}\end{array}$ \\
\hline 5 & 600 & 2,6 & 525 & 2,7 & 485 & 2,9 \\
\hline 6 & 735 & 3,0 & 600 & 3,0 & 585 & 3,2 \\
\hline 7 & 385 & 2,0 & 290 & 2,0 & 280 & 2,2 \\
\hline 8 & 885 & 3,4 & 765 & 3,4 & 605 & 3,2 \\
\hline
\end{tabular}

\begin{tabular}{|c|c|c|c|c|c|c|}
\cline { 2 - 7 } \multicolumn{1}{c|}{} & \multicolumn{9}{c|}{ heating time } \\
\cline { 2 - 7 } \multicolumn{1}{c|}{} & \multicolumn{2}{c|}{$1800 \mathrm{~s}$} & \multicolumn{2}{c|}{$2700 \mathrm{~s}$} & \multicolumn{2}{c|}{$3600 \mathrm{~s}$} \\
\hline $\begin{array}{c}\text { void } \\
\text { no. }\end{array}$ & $\begin{array}{c}\mathrm{t}_{\Delta \mathrm{Tmax}} \\
\text { in s }\end{array}$ & $\begin{array}{c}\text { depth } \\
\text { in cm }\end{array}$ & $\begin{array}{c}\mathrm{t}_{\Delta \mathrm{Tmax}} \\
\text { in s }\end{array}$ & $\begin{array}{c}\text { depth } \\
\text { in } \mathrm{cm}\end{array}$ & $\begin{array}{c}\mathrm{t}_{\Delta \mathrm{Tmax}} \\
\text { in s }\end{array}$ & $\begin{array}{c}\text { depth } \\
\text { in } \mathrm{cm}\end{array}$ \\
\hline 5 & 325 & 2,8 & 300 & 3,1 & 285 & 3,3 \\
\hline 6 & 390 & 3,1 & 330 & 3,2 & 295 & 3,4 \\
\hline 7 & 160 & 2,1 & - & - & - & - \\
\hline 8 & 515 & 3,5 & 370 & 3,4 & 350 & 3,6 \\
\hline
\end{tabular}

Table 3: Nominal depth and mean depth determined by Inverse Solution.

\begin{tabular}{|c|c|c|}
\hline $\begin{array}{c}\text { void } \\
\text { no. }\end{array}$ & $\begin{array}{c}\text { nominal depth } \\
\text { in } \mathrm{cm}\end{array}$ & $\begin{array}{c}\text { mean depth from Inverse Solution } \\
\text { in } \mathrm{cm}\end{array}$ \\
\hline 5 & 2,0 & $2,9 \pm 0,4$ \\
\hline 6 & 4,0 & $3,1 \pm 0,3$ \\
\hline 7 & 6,0 & $2,1 \pm 0,1$ \\
\hline 8 & 8,0 & $3,4 \pm 0,2$ \\
\hline
\end{tabular}

Table 3 shows a comparison between nominal depth and mean depth as a result from Inverse Solution. Obviously, the values of both depths do not match for each single defect. The real depth might have changed related to the nominal depth during concreting. For data validation, it is planned to destroy the test specimen in the future.

\section{Conclusion and Outlook}

Impulse thermography can be used as a good tool for non-destructive testing in civil engineering. Locating defects in concrete with concrete covers up to $10 \mathrm{~cm}$ has been performed successfully. It is a very fast and efficient non-destructive method, which can 
be used contactless giving direct images of the surface. A quantitative analysis of the experimental data can be carried out.

Numerical simulations are useful to investigate the influence of environmental conditions and material parameters and to determine the depth of real voids by comparing simulated and measured values (Inverse Problem).

Further investigations have shown that the method can also be applied for the detection of delaminations of surface layers (plaster on concrete and masonry, carbon reinforced laminates on concrete, cleaving tiles embedded in mortar on concrete) and for locating enhanced moisture in the surface near region [10].

In the future, the influence of moisture and reinforcement on detecting voids and honeycombing will be analysed. Besides, investigations and data analysis based on pulsed phased thermography in addition to impulse thermography measurements are planned.

\section{Acknowledgements}

The presented work was supported by the DFG within the research project "Investigation of structure and moisture content in the surface near region of building structures with impulse thermography" (WI 1785/1-1/2).

\section{REFERENCES}

[1] Maldague, X. P. V: Nondestructive evaluation of materials by infrared thermography, 1st Title, London, Springer-Verlag, 1993.

[2] Danesi, S., Salerno, A., Wu, D. and Busse, G.: Cooling-down thermography: principle and results in NDE, in: Proceedings of the International Society for Optical Engineering, Thermosense XX, J. R. Snell and R. N. Wurzbach (eds.), Orlando, 1998, pp. 266-274.

[3] Weise, F., Arndt, D., Borchardt, K., Geyer, E., Henschen, J., Krause. M. and NiedackNad, M.: Non-Destructive Testing Methods for Determining the Built-in Position of Anchoring Elements at Curtain Facades, in: Proceedings of the Int. Symp. on NonDestructive Testing in Civil Engineering (NDT-CE), G. Schickert and $\mathrm{H}$. Wiggenhauser (eds.), Vol. 1, DGZfP, Berlin, 1995, pp. 867-876.

[4] Bjegovic, D., Mikulic, D. and Sekulic, D.: Non-destructive methods for monitoring of reinforcing steel in concrete, in: Forde, M. C., Proceedings of Structural Faults and Repair 2001, London, CDROM

[5] Stimolo, M.: Praktische Anwendung der Thermografie im Straßenbau und für Abdichtungssysteme, in: DGZfP-Berichtsband 77-CD, Thermografie-Kolloquium 2001, Stuttgart

[6] ASTM Standard D4788-88 (reapproved 1997): Standard Test Method for Detecting Delaminations in Bridge Decks Using Infrared Thermography.

[7] Vavilov, V., Kauppinen, T. and Grinzato, E.: Thermal characterisation of defects in building envelopes using long square pulse and slow thermal wave techniques, Research Non-Destructive Evaluation 9, 1997, pp. 181-200.

[8] Geyer, E., Arndt, D. and Wiggenhauser, H.: Anwendung der Transient-Thermografie im Bauwesen, in: GMA-Bericht 29, GESA-Symposium 1996, Experimentelle Beanspruchungsanalyse - neue Entwicklungen und Anwendungen, VDI/VDE-GMA, Düsseldorf, 1996, pp. 351-352.

[9] Maierhofer, Ch., Brink, A., Röllig, M. and Wiggenhauser, H.: Transient thermography for structural investigation of concrete and composites in the near surface region, Infrared Physics and Technology 43, 2002, pp. 271-278.

[10] Brink, A., Maierhofer, Ch., Röllig, M. and Wiggenhauser, H.: Struktur- und Feuchteuntersuchung von Bauteil- und Bauwerksoberflächen mit der ImpulsThermografie, Zwischenbericht des DFG-Projektes, 2001, unpublished. 